\title{
Androgen deprivation therapy during and after post-prostatectomy radiotherapy in patients with prostate cancer: a case control study
}

Myong Kim', Cheryn Song ${ }^{1}$, In Gab Jeong ${ }^{1}$, Seung-Kwon Choi ${ }^{1}$, Myungchan Park', Myungsun Shim', Young Seok Kim², Dalsan You', Jun Hyuk Hong ${ }^{1}$, Choung-Soo Kim ${ }^{1}$ and Hanjong Ahn ${ }^{1 *}$

\begin{abstract}
Background: Here we assessed the influence of androgen deprivation therapy (ADT) during and/or after postprostatectomy radiotherapy (RT) on biochemical recurrence (BCR) and radiographic progression in patients with prostate cancer.

Methods: Patients with prostate cancer who underwent post-prostatectomy RT were analyzed. BCR and radiographic progression after RT were compared according to the concurrent or salvage ADT. Cox regression analyses were used to identify risk factors for BCR and radiographic progression.

Results: Of the 227 patients who underwent post-prostatectomy RT, 95 (41.9\%) received concurrent ADT for a median of 17.0 months. Despite more aggressive disease characteristics in the concurrent ADT group than in the RT-only group, the former had a better 5-year BCR-free survival rate than the latter (66.1 vs. 53.9\%; $p=0.016$ ), whereas the radiographic progression rate was not significantly different between two groups. On the other hand, salvage ADT after post-RT BCR significantly delayed radiographic progression (5-year radiographic progression-free survival; 75.2 vs. $44.5 \% ; p=0.002$ ).
\end{abstract}

Conclusions: Concurrent ADT improved BCR-free survival, and salvage ADT after post-RT BCR improved radiographic progression-free survival. To maximize the oncological benefit, ADT of sufficient duration should be implemented.

Keywords: Radiotherapy, Androgen-deprivation therapy, Prostate cancer, Survival, Prognostic factor

\section{Background}

Despite the stage migration in prostate cancer noted in this prostate specific antigen (PSA) screening era, extraprostatic disease continues to occur in more than onethird of patients who undergo radical prostatectomy (RP) $[1,2]$. Post-prostatectomy radiotherapy (RT) is advocated as a viable treatment option in both the adjuvant and salvage settings [3-5].

Three contemporary randomized controlled trials (RCTs) investigating adjuvant RT vs. observation after

\footnotetext{
* Correspondence: hjahn@amc.seoul.kr

${ }^{1}$ Department of Urology, Asan Medical Center, University of Ulsan College of Medicine, 88 Olympic-ro 43-gil, Songpa-gu, Seoul 05505, Republic of Korea

Full list of author information is available at the end of the article
}

RP, namely the SWOG 8794 [6], EORTC 22911 [7], and ARO 96-02 [8], demonstrated that adjuvant RT reduced the risks of biochemical recurrence (BCR) and local relapse by approximately $20 \%$ at 5 years among patients with adverse pathologic features (i.e., seminal vesicle invasion, positive surgical margins with or without extraprostatic extension). The results of some large observational studies have indicated that salvage RT effectively controls locally recurrent disease after RP $[9,10]$.

However, patients with adverse pathologic characteristics or those who experience PSA recurrences after RP can harbor micrometastases that cannot be detected by imaging. In these cases, it may be beneficial to combine 
supplementary androgen deprivation therapy (ADT) with local RT, a notion being tested by several RCTs [11-15]. The final results from the RTOG 9601 showed that adding a 24 month anti-androgen (AA) treatment during salvage RT reduced mortality over a median follow-up of 12.6 years compared with salvage RT-only treatment (12-year overall survival [OS]: 76.3 vs. $71.3 \%$; $p=0.04)$ [15] .

Long-term ADT can reduce quality of life and increase the risk of adverse events, including gynecomastia, cardiovascular accidents, fractures, and metabolic syndrome [15-19]. In this regard, the recent results from the GETUG-AFU 16 trial demonstrated that 6 months of luteinizing hormone releasing hormone (LHRH) agonist treatment during salvage RT significantly reduced clinical progression (5-year progression-free survival, 80.0 vs. 62.0\%; $p<0.0001$ ) [14]. These results are noteworthy as they support the survival benefit of concurrent ADT with post-prostatectomy RT.

However, previous RCT results did not conclude whether short-term ADT has an oncologic benefit equal to that of long-term ADT during post-prostatectomy RT [11-15]. Moreover, because the protocols of previous RCTs stated that salvage ADT should only be administered in cases of radiographic or pathologic evidence of metastatic disease [11, 12], they did not determine whether the androgen axis suppression that occurs by supplementary ADT can delay the next disease progression phase, such as radiographic progression after post-RT BCR. Here we assessed the oncological benefit of supplementary ADT during or after postprostatectomy RT.

\section{Methods}

\section{Patient selection}

This study was approved by our institutional review board. The study population comprised 336 consecutive patients who underwent adjuvant or salvage RT following RP between August 1998 and March 2013. The exclusion criteria were the presence of other malignancies $(n=4,1.2 \%)$, ineligibility according to American Society for Radiation Oncology (ASTRO)/ American Urological Association (AUA) criteria for adjuvant or salvage RT [3] $(n=1,0.3 \%)$, the administration of neoadjuvant ADT before RP $(n=7,2.1 \%)$, failure to complete the planned RT dose $(n=2$, $0.6 \%$, and incomplete clinical data or loss to followup $(n=15,4.5 \%)$. Patients whose PSA levels did not decline to undetectable levels $(<0.2 \mathrm{ng} / \mathrm{mL})$ after $\mathrm{RP}$ $(n=80,23.8 \%)$ were also excluded to ensure that the pure impact of supplementary ADT on the prognostic outcomes from post-prostatectomy RT was evaluated. Thus, 227 patients (67.6\%) were included in the final analysis.

\section{Definitions and data acquisition}

Adjuvant and salvage RT were defined according to the recent ASTRO/AUA criteria. Adjuvant RT was the administration of RT to RP patients who had adverse pathologic characteristics (pT2 with positive surgical margins, pT3, or pN1), prior to the PSA recurrence. Salvage RT was the administration of RT to patients with PSA recurrences after surgery without evidence of systemic disease [3].

Supplementary ADT was classified into concurrent and salvage ADT according to time of administration. Concurrent ADT was defined as ADT administered before, concurrent with, or after RT. Salvage ADT was defined as ADT administered after a post-RT BCR. The ADT regimens were manipulated according to PSA response. When castration resistance occurred, further treatments, including cytotoxic chemotherapy, were initiated, based on the physician's decision.

Clinical variables during follow-up were retrieved from the patients' medical records. The original [20] or revised [21] Gleason score criteria were applied according to the time of diagnosis. Tumor-lymph node-metastasis staging was determined using the revised American Joint Cancer Committee criteria [22].

\section{Statistical analyses}

The concurrent ADT plus RT group and RT-only group were compared with respect to BCR-free survival from the date of RT. Radiographic progression-free survival was compared in the salvage and no salvage ADT groups; these groups comprised patients who experienced postRT BCR $(n=81)$. Cox proportional hazards analyses were used to determine whether concurrent or salvage ADT affected BCR-free or radiographic progression-free survival. All tests were two-tailed with a significance level of $<0.05$. The statistical analyses were performed using $\mathrm{SPSS}^{\odot}$ software version 21.0 (IBM Corporation, Armonk, NY, USA).

\section{Results \\ Patient characteristics}

Of the 227 patients who underwent post-prostatectomy RT, 95 (41.9\%) received concurrent ADT for a median 17.0 months (interquartile range [IQR], 12.5-22.0 months) (Table 1). Compared to the RT-only group, the concurrent ADT group had unfavorable clinical characteristics such as more frequent $\mathrm{pN} 1$ disease (12.6 vs. $3.0 \%)$ and higher pre-RT PSA level ( 0.72 vs. $0.39 \mathrm{ng} / \mathrm{mL}$; Table 1$)$. Of the 81 patients who experienced post-RT BCR, 50 patients (61.7\%) received salvage ADT for a median 16.0 months (IQR, 3.8-51.3 months). The salvage ADT group was younger (61.0 vs. 65.0 years) and had a higher pre-RT PSA level (0.71 vs. $0.42 \mathrm{ng} / \mathrm{mL})$ than the non-salvage ADT 
Table 1 Comparisons of clinicopathologic characteristics of each sub-group categorized by the modes of supplementary androgen deprivation therapy during post-prostatectomy radiotherapy

\begin{tabular}{|c|c|c|c|c|c|c|}
\hline & \multicolumn{3}{|l|}{ All patients $(n=227)$} & \multicolumn{3}{|c|}{ Patients with post-radiotherapy BCR $(n=81)$} \\
\hline & No concomitant ADT & Concurrent ADT & $p$-value ${ }^{a}$ & No salvage ADT & Salvage ADT & $p$-value ${ }^{a}$ \\
\hline Number of patients & 132 & 95 & - & 31 & 50 & - \\
\hline \multicolumn{7}{|l|}{ Patients characteristics } \\
\hline Age (years) & $64.0(59.3-68.0)$ & $64.0(59.0-70.0)$ & 0.500 & $65.0(61.0-70.0)$ & $61.0(58.0-65.0)$ & 0.012 \\
\hline Pre-operative PSA (ng/mL) & $12.60(7.00-22.90)$ & $9.90(6.90-18.90)$ & 0.690 & $16.33(6.40-28.00)$ & $11.00(6.55-25.20)$ & 0.711 \\
\hline \multicolumn{7}{|l|}{ Pathology-related factors } \\
\hline Gleason score & $7(7-9)$ & $7(7-9)$ & 0.385 & $8(7-9)$ & $7(7-9)$ & 0.411 \\
\hline Pathologic $T$ stage $\geq 3 a$ & $89(67.4 \%)$ & $56(58.9 \%)$ & 0.190 & $19(61.3 \%)$ & $36(72.0 \%)$ & 0.316 \\
\hline Pathologic N stage $\geq 1$ & $4(3.0 \%)$ & $12(12.6 \%)$ & 0.005 & $2(6.5 \%)$ & $1(2.0 \%)$ & 0.302 \\
\hline Tumor volume (\%) & $10.0(1.0-20.0)$ & $9.0(1.0-17.0)$ & 0.504 & $9.0(1.0-20.0)$ & $2.0(1.0-16.0)$ & 0.110 \\
\hline Positive surgical margin & $81(61.4 \%)$ & $59(62.1 \%)$ & 0.910 & $19(61.3 \%)$ & $27(54.0 \%)$ & 0.520 \\
\hline \multicolumn{7}{|l|}{ ADT-related factors } \\
\hline Concomitant ADT duration (months) & - & $17.0(12.0-21.0)$ & - & - & - & - \\
\hline Salvage ADT duration (months) & - & - & - & - & $16.0(3.8-51.3)$ & - \\
\hline \multicolumn{7}{|l|}{ Initial regimen } \\
\hline Complete androgen blockage & - & $43(45.3 \%)$ & - & - & $8(16.0 \%)$ & \\
\hline LHRH agonist & - & $31(32.6 \%)$ & & - & $32(64.0 \%)$ & \\
\hline Antiandrogen & - & $21(22.1 \%)$ & & - & $10(20.0 \%)$ & \\
\hline Radiotherapy-related factors & & & & - & & \\
\hline Pre-radiotherapy PSA (ng/mL) & $0.39(0.25-0.60)$ & $0.72(0.50-1.10)$ & $<0.001$ & $0.42(0.32-0.75)$ & $0.71(0.39-1.63)$ & 0.007 \\
\hline Radiotherapy dose (Gy) & $66.0(66.0-70.0)$ & $66.0(66.0-66.0)$ & 0.117 & $66.0(66.0-70.0)$ & $66.0(66.0-70.0)$ & 0.607 \\
\hline
\end{tabular}

$A D T$ androgen deprivation therapy, $B C R$ biochemical recurrence, $P S A$ prostate specific antigen, $L H R H$ luteinizing hormone releasing hormone All values are median (interquartile range) or the number (\%)

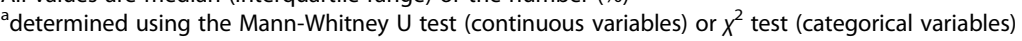

group. Other baseline characteristics did not differ between the two groups (Table 1).

\section{Effect of concurrent ADT on BCR}

The median follow-up was 84.2 months (IQR, 59.3108.9 months) from RP and 50.8 months (IQR, 36.3-66.8 months) from the post-prostatectomy RT. During follow-up, 81 patients (35.7\%) experienced BCR and 38 (16.7\%) showed radiographic progression. Of the patients with radiographic progression, 17 patients (7.5\%) had local recurrence and 21 (9.3\%) had distant metastases, respectively. The overall 5-year BCR-free and radiographic progression-free survival rates after post-prostatectomy RT were $59.0 \%$ and $84.0 \%$, respectively.

The concurrent ADT group showed better 5-year BCRfree survival rate than the no concurrent ADT group (66.1 vs. $53.9 \%$; $p=0.016$; Fig. 1 ). Concurrent ADT (hazard ratio $[\mathrm{HR}]=0.381 ; p=0.034$ ) was an independent prognostic factor for BCR after $\mathrm{RT}$, along with pre-RT PSA level $(\geq 1.0 \mathrm{ng} / \mathrm{mL} ; \mathrm{HR}=4.383 ; p=0.001$; Table 2$)$.

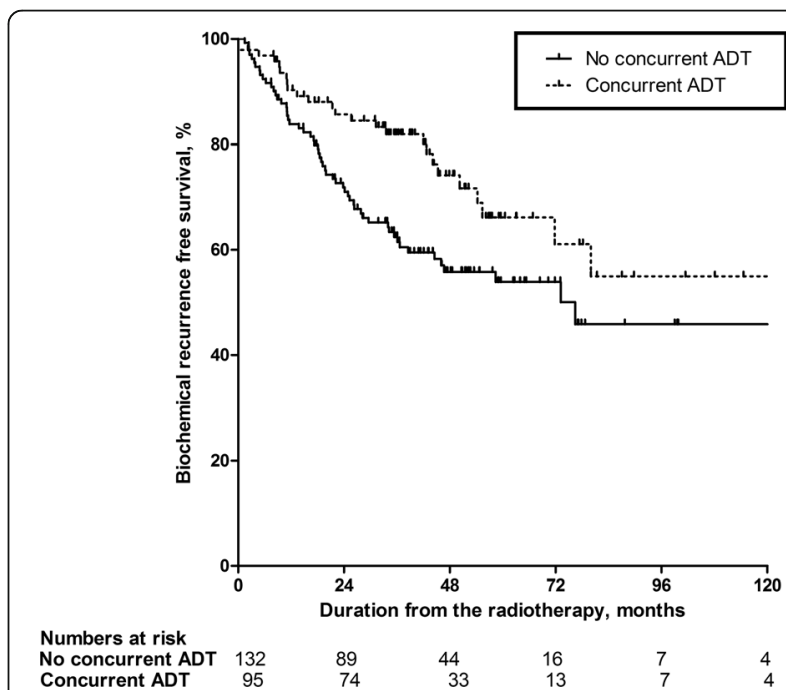

Fig. 1 Comparison of the concurrent and no concurrent androgen deprivation therapy (ADT) groups with respect to biochemical recurrence $(B C R)$-free survival form the date of radiotherapy.The estimated 5-year BCR-free survival rates for the no concurrent and concurrent ADT groups were $53.9 \%$ and $66.1 \%(p=0.016)$, respectively 
Table 2 Cox regression analysis of biochemical recurrence in patients treated with post-prostatectomy radiotherapy

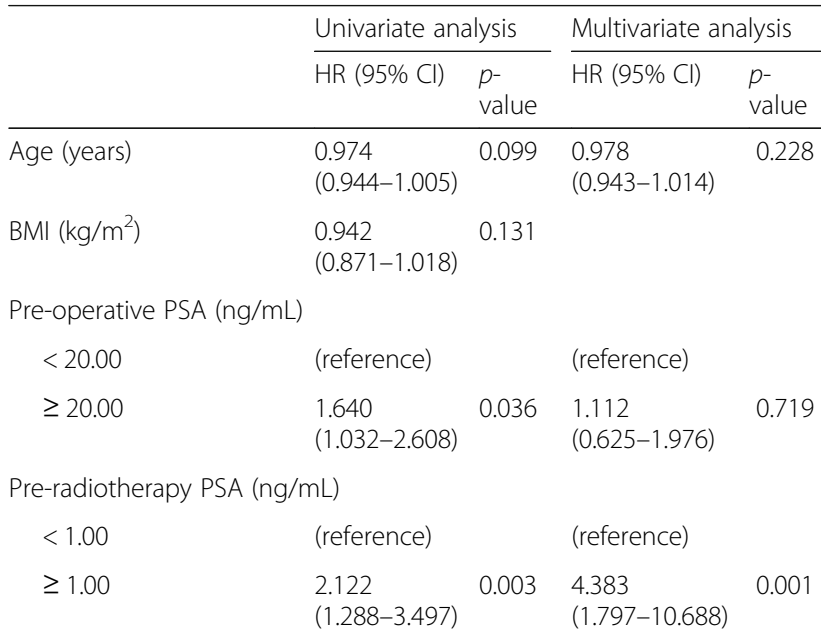

Pathologic Gleason score

$\begin{array}{lll}\leq 7 & \text { (reference) } & \\ \geq 8 & 1.393 & 0.140 \\ & (0.897-2.163) & \end{array}$

Pathologic T stage

$\begin{array}{lll}\leq \text { pT2 } & \text { (reference) } & \\ \geq \text { pT3 } & 1.272 & 0.312 \\ & (0.798-2.029) & \end{array}$

Pathologic N stage

pNO or pNx

(reference)

$\mathrm{pN1}$

0.498

(0.157-1.579)

Tumor volume (\%)

$$
\begin{array}{lll}
<10.0 & \text { (reference) } & \\
\geq 10.0 & 0.939 & 0.783 \\
& (0.600-1.469) &
\end{array}
$$

Surgical margin tumor involvement

$\begin{array}{lll}\text { Negative } & \text { (reference) } & \\ \text { Positive } & 0.815 & 0.363 \\ & (0.525-1.266) & \end{array}$

Radiation dose (Gy)

$\begin{array}{lll}<66.0 & \text { (reference) } & \\ \geq 66.0 & 0.770 & 0.424 \\ & (0.406-1.461) & \end{array}$

after RP $(\mathrm{ng} / \mathrm{mL}) \quad(0.948-1.248)$

$\begin{array}{lllll}\text { Duration of } & 0.984 & 0.031 & 0.991 & 0.361\end{array}$

unrecovered testosterone $(0.970-0.998) \quad(0.971-1.011)$

level (months)

Concurrent ADT

\begin{tabular}{lllll} 
No & (reference) & & (reference) & \\
Yes & 0.564 & 0.018 & 0.381 & 0.034 \\
& $(0.352-0.905)$ & & $(0.157-0.927)$ & \\
\hline
\end{tabular}

$H R$ hazard ratio, $C l$ confidence interval, $B M I$ body mass index, $P S A$ prostate specific antigen, $R P$ radical prostatectomy, $A D T$ androgen deprivation therapy

\section{Effect of salvage ADT on radiographic progression}

A total of 81 patients experienced post-RT BCR, and the salvage ADT group showed better 5-year radiographic progression-free survival than the no salvage ADT group (75.2 vs. $44.5 \% ; p=0.002$; Fig. 2 ). The multivariate analysis demonstrated that salvage ADT $(\mathrm{HR}=0.306 ; \mathrm{p}=0.001)$ was an independent prognostic factor for radiographic progression, along with the $\mathrm{pN}$ stage $(\mathrm{pN} 1 ; \mathrm{HR}=16.457 ; \mathrm{p}=0.001)$, and the tumor volume $(\geq 10.0 \% ; \mathrm{HR}=4.137 ; p<0.001$; Table 3$)$. However, previous administrations of concurrent ADT did not affect radiographic progression (univariate analysis; $p=0.725$; Table 3 ).

\section{Discussion}

\section{Concurrent ADT with post-prostatectomy RT}

Previous RCTs such as the RTOG 9601 [15] and GETUGAFU 16 [14] reported that compared with salvage RT-only, long-term (24 months [15]) or short-term (6 months [14]) ADT with salvage RT significantly improved BCR. In this study, we also confirmed the benefit of current ADT in terms of BCR-free survival. However, there have been limited data on the proper duration of concurrent ADT during post-prostatectomy RT. Short-term (<12 months) concurrent ADT was reportedly associated with increases in $\mathrm{BCR}(\mathrm{HR}=2.27$; $p=0.003)$ and distant metastasis $(\mathrm{HR}=2.48 ; p=0.03)$ compared with longer-term ( $\geq 12$ months) ADT [23]. With respect to ADT duration, we found that patients who underwent $<12$ months of concurrent ADT showed poorer 5-year BCR-free survival than

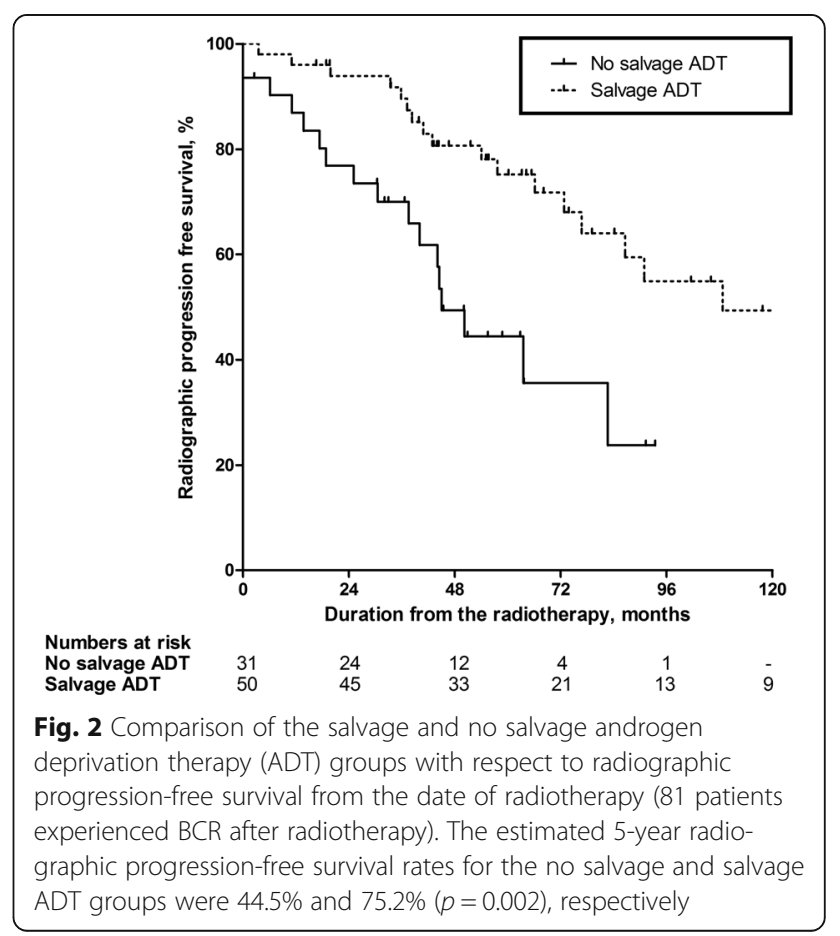


Table 3 Cox regression analysis of radiographic progression in patients treated with post-prostatectomy radiotherapy $(n=81)$ who experienced biochemical recurrence after radiotherapy

\begin{tabular}{|c|c|c|c|c|}
\hline & \multicolumn{2}{|c|}{ Univariate analysis } & \multicolumn{2}{|c|}{ Multivariate analysis } \\
\hline & $\mathrm{HR}(95 \% \mathrm{Cl})$ & $p$-value & $\mathrm{HR}(95 \% \mathrm{Cl})$ & $p$-value \\
\hline Age (years) & $\begin{array}{l}1.035 \\
(0.978-1.096)\end{array}$ & 0.231 & & \\
\hline $\mathrm{BMI}\left(\mathrm{kg} / \mathrm{m}^{2}\right)$ & $\begin{array}{l}0.913 \\
(0.773-1.078)\end{array}$ & 0.282 & & \\
\hline \multicolumn{5}{|c|}{ Pre-operative PSA (ng/mL) } \\
\hline$<20.00$ & (reference) & & & \\
\hline$\geq 20.00$ & $\begin{array}{l}1.111 \\
(0.551-2.241)\end{array}$ & 0.768 & & \\
\hline \multicolumn{5}{|c|}{ Pre-radiotherapy PSA (ng/mL) } \\
\hline$<1.00$ & (reference) & & & \\
\hline$\geq 1.00$ & $\begin{array}{l}0.906 \\
(0.427-1.923)\end{array}$ & 0.796 & & \\
\hline
\end{tabular}

Pathologic Gleason score

$\begin{array}{lllll}\leq 7 & \text { (reference) } & & \text { (reference) } & \\ \geq 8 & 2.438 & 0.017 & 1.288 & 0.482 \\ & (1.169-5.084) & & (0.636-2.609) & \end{array}$

Pathologic T stage

$\leq$ pT2 $\quad$ (reference)

$\geq$ pT3 $\quad 1.262$

(0.599-2.659)

0.540

Pathologic N stage

$\begin{array}{llll}\mathrm{pN} 0, \text { or pNx } & \text { (reference) } & & \text { (reference) } \\ \mathrm{pN1} & 6.096 & 0.021 & 16.457 \\ & (1.316-28.234) & & (3.358-80.652)\end{array}$

Tumor volume (\%)

$$
\begin{array}{ll}
<10.0 & \text { (reference) } \\
\geq 10.0 & 3.888 \\
& (1.923-7.862)
\end{array}
$$

$<0.001$

(reference)

4.137

$(1.999-8.562)$

Surgical margin tumor involvement

Negative (reference)

Positive $\quad 1.678$

$(0.819-3.437)$

Radiation dose (Gy)

$<66.0 \quad$ (reference)

$\geq 66.0 \quad 1.564$

(0.619-3.951)

Testosterone nadir $\quad 1.170$

after RP $(\mathrm{ng} / \mathrm{mL}) \quad(0.834-1.643)$

Duration of

1.002

$(0.989-1.015)$

unrecovered

testosterone

level (months)

Concurrent ADT

$\begin{array}{lll}\text { No } & \text { (reference) } & \\ \text { Yes } & 1.134 & 0.725 \\ & (0.563-2.287) & \end{array}$

Table 3 Cox regression analysis of radiographic progression in

\begin{tabular}{|c|c|c|c|c|}
\hline & \multicolumn{2}{|c|}{ Univariate analysis } & \multicolumn{2}{|c|}{ Multivariate analysis } \\
\hline & $\mathrm{HR}(95 \% \mathrm{Cl})$ & $p$-value & HR $(95 \% \mathrm{Cl})$ & $p$-value \\
\hline \multicolumn{5}{|c|}{ Salvage ADT } \\
\hline No & (reference) & & (reference) & \\
\hline Yes & $\begin{array}{l}0.344 \\
(0.171-0.692)\end{array}$ & 0.003 & $\begin{array}{l}0.306 \\
(0.150-0.627)\end{array}$ & 0.001 \\
\hline
\end{tabular}
patients treated with post-prostatectomy radiotherapy $(n=81)$ who experienced biochemical recurrence after radiotherapy (Continued)

$H R$ hazard ratio, $\mathrm{Cl}$ confidence interval, $B M I$ body mass index, PSA prostate specific antigen, $R P$ radical prostatectomy, $A D T$ androgen deprivation therapy

patients who underwent longer-term ( $\geq 12$ months) ADT, although the difference failed to reach statistical significance ( $p=0.232$; Appendix). These findings concur with the results of a previous study [23]. These findings suggest that the concurrent ADT duration should be extended to 12 months or longer.

\section{Role of salvage ADT}

The RTOG 9601 study protocol stated that salvage ADT should only be administered when there is radiographic or pathologic evidence of metastatic disease [11]. The administration of salvage ADT was not restricted in this way in our study; consequently, a substantial proportion of the patients who developed post-RT BCR (61.7\%) were administered salvage ADT. Clearly, the strict specifications of the RTOG 9601 were necessary to determine the pure effects of concurrent ADT in a post-prostatectomy RT setting; however, our study resembles real-life practice more closely.

In real clinical practice, $\mathrm{ADT}$ is not only delivered concurrently with RT. Indeed, when post-RT BCR occurs, salvage ADT may be considered a viable treatment option in patients with hormone-naïve or hormone-sensitive prostate cancer $[4,5]$. The oncological role of salvage ADT after post-RT BCR remains unclear. Given that there are numerous instances of salvage ADT in clinical settings, it is also important to determine whether salvage ADT can benefit patients with post-RT BCR. Our results demonstrated that salvage ADT independently improved radiographic progression $(\mathrm{HR}=0.306$; $p=0.001$; Table 3). Previous administrations of concurrent ADT did not affect radiographic progression (univariate analysis: $p=0.725$; Table 3 ). These findings strongly imply that the differences in the radiographic progression in the salvage ADT group were also caused by the direct suppression of the androgen axis by the salvage ADT itself. Hence, we suggest that salvage $A D T$ can be a viable treatment option that may alter radiographic progression when BCR occurs after 
post-prostatectomy RT in patients with hormonenaïve or hormone-sensitive prostate cancer.

\section{Limitations of the current study}

Our study was limited by its retrospective nature and the relatively small number of patients included. In addition, information for some of the variables was absent, because some of the patients' medical records were incomplete. Moreover, the effects of the different types of ADT applied to the study cohort on BCR and radiographic progression were not considered. This reflects the fact that, in most patients, the ADT regimen was manipulated based on the PSA levels, which resulted in substantial regimen heterogeneity that precluded closer analyses.

\section{Conclusions}

Concurrent ADT during post-prostatectomy RT significantly improved BCR-free survival, and salvage ADT after post-RT BCR improved radiographic progression-free survival. Therefore, to maximize the oncological benefit, ADT of sufficient durations should be implemented, and salvage ADT should be considered as a viable treatment option after post-RT $\mathrm{BCR}$. The results from ongoing RCTs are needed to confirm our results.

\section{Appendix}

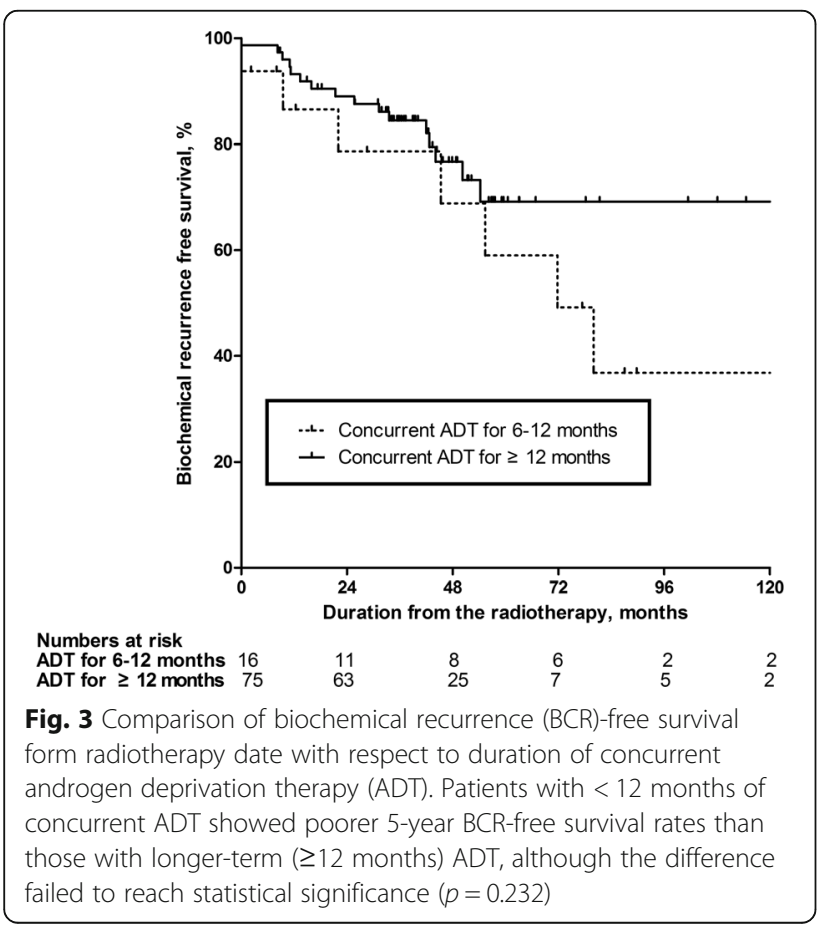

\section{Abbreviations}

AA: Anti-androgen; ADT: Androgen deprivation therapy; ASTRO: American Society for Radiation Oncology; AUA: American Urological Association; BCR: Biochemical recurrence; HR: Hazard ratio; IQR: Interquartile range; LHRH: Luteinizing hormone releasing hormone; OS: Overall survival; PSA: Prostate specific antigen; RCT: Randomized controlled trial; RP: Radical prostatectomy; RT: Radiotherapy

\section{Acknowledgements}

The authors have none to declare.

\section{Funding}

This research did not receive any specific grant from funding agencies in the public, commercial, or not-for-profit sectors.

\section{Availability of data and materials}

The release of patient data to the public is not possible. Our IRB approved this study with the condition that the security of patient personal information be strictly maintained. Therefore, the release of patient data to the public would be a violation of IRB terms of approval. Instead, researchers interested in data from this study can contact the corresponding author (Hanjong Ahn; E-mail: hjahn@amc.seoul.kr). Upon request, researchers may be provided the data to an extent that this does not violate IRB regulations.

\section{Authors' contributions}

MK, SKC, and HA conceived and designed the study. MK, CS, IGJ, SKC, MP, MS, and DY collected patient's data. MK, SKC, and HA analyzed most data. $M K, C S$, and HA wrote the manuscript with contributions from all authors. YSK, JHH, and CSK provide critical comments for this manuscript. All authors read and approved the manuscript.

\section{Ethics approval and consent to participate}

This study was approved by the institutional review board of Asan Medical Center (Approval No. S2015-0709-0002), Seoul, South Korea. The need for informed consent was waived by the institutional review board because of the minimal risk for potential harms. All personal information was anonymized before analysis.

\section{Consent for publication}

Not applicable.

\section{Competing interests}

The authors declare that they have no competing interests.

\section{Publisher's Note}

Springer Nature remains neutral with regard to jurisdictional claims in published maps and institutional affiliations.

\section{Author details}

${ }^{1}$ Department of Urology, Asan Medical Center, University of Ulsan College of Medicine, 88 Olympic-ro 43-gil, Songpa-gu, Seoul 05505, Republic of Korea. ${ }^{2}$ Department of Radiation Oncology, Asan Medical Center, University of Ulsan College of Medicine, Seoul, Republic of Korea.

Received: 18 May 2017 Accepted: 6 March 2018

Published online: 09 March 2018

\section{References}

1. Bott SRJ, Freeman AA, Stenning S, Cohen J, Parkinson MC. The urologists pathologists contributing to the database: radical prostatectomy: pathology findings in 1001 cases compared with other major series and over time. BJU Int. 2005;95(1):34-9.

2. Ward JF, Blute ML, Slezak J, Bergstralh EJ, Zincke H. The long-term clinical impact of biochemical recurrence of prostate cancer 5 or more years after radical prostatectomy. J Urol. 2003;170(5):1872-6.

3. Thompson IM, Valicenti RK, Albertsen P, Davis BJ, Goldenberg SL, Hahn C, Klein E, Michalski J, Roach M, Sartor O, et al. Adjuvant and salvage radiotherapy after prostatectomy: AUA/ASTRO guideline. J Urol. 2013;190(2):441-9.

4. Heidenreich A, Bastian PJ, Bellmunt J, Bolla M, Joniau S, van der Kwast T, Mason M, Matveev V, Wiegel T, Zattoni F, et al. EAU guidelines on prostate 
cancer. Part II: treatment of advanced, relapsing, and castration-resistant prostate cancer. Eur Urol. 2014;65(2):467-79.

5. Mohler UL, Kantoff PW, Armstrong AJ, Bahnson RR, Cohen M, D'Amico AV, Eastham JA, Enke CA, Farrington TA, Higano CS, et al. Prostate cancer, version 2.2014. J Natl Compr Cancer Netw. 2014;12(5):686-718.

6. Thompson IM, Tangen CM, Paradelo J, Lucia MS, Miller G, Troyer D, Messing E, Forman J, Chin J, Swanson G. Adjuvant radiotherapy for pathologically advanced prostate cancer: a randomized clinical trial. JAMA. 2006;296(19):2329-35.

7. Bolla M, van Poppel H, Tombal B, Vekemans K, Da Pozzo L, de Reijke TM, Verbaeys A, Bosset J-F, van Velthoven R, Colombel M, et al. Postoperative radiotherapy after radical prostatectomy for high-risk prostate cancer: longterm results of a randomised controlled trial (EORTC trial 22911). Lancet. 2005;380(9858):2018-27.

8. Wiegel T, Bottke D, Steiner U, Siegmann A, Golz R, Storkel S, Willich N, Semjonow A, Souchon R, Stockle M, et al. Phase III postoperative adjuvant radiotherapy after radical prostatectomy compared with radical prostatectomy alone in $\mathrm{pT} 3$ prostate cancer with postoperative undetectable prostate-specific antigen: ARO 96-02/AUO AP 09/95. J Clin Oncol. 2009;27(18):2924-30.

9. Trock BJ, Han M, Freedland SJ, et al. Prostate cancer-specific survival following salvage radiotherapy vs observation in men with biochemical recurrence after radical prostatectomy. JAMA. 2008;299(23):2760-9.

10. Boorjian SA, Karnes RJ, Crispen PL, Rangel LJ, Bergstralh EJ, Blute ML. Radiation therapy after radical prostatectomy: impact on metastasis and survival. J Urol. 2009;182(6):2708-15.

11. 9601 A Phase III Trial of radiation therapy with or without casodex in patients with PSA elevation following radical prostatectomy for pT3NO carcinoma of the prostate [http://www.rtog.org/ClinicalTrials/ProtocolTable.aspx].

12. 0534 A Phase III Trial of short term androgen deprivation with pelvic lymph node or prostate bed only radiotherapy (SPPORT) in prostate cancer patients with a rising PSA after radical prostatectomy [http://www.rtog.org/ ClinicalTrials/ProtocolTable.aspx].

13. Parker C, Clarke N, Logue J, Payne H, Catton C, Kynaston H, Murphy C, Morgan R, Morash C, Parulekar W. RADICALS (radiotherapy and androgen deprivation in combination after local surgery). Clin Oncol. 2007;19(3):167-71.

14. Carrie C, Hasbini A, de Laroche G, Richaud P, Guerif S, Latorzeff I, Supiot S, Bosset M, Lagrange JL, Beckendorf $V$, et al. Salvage radiotherapy with or without short-term hormone therapy for rising prostate-specific antigen concentration after radical prostatectomy (GETUG-AFU 16): a randomised, multicentre, open-label phase 3 trial. Lancet Oncol. 2016;17(6):747-56.

15. Shipley WU, Seiferheld W, Lukka HR, Major PP, Heney NM, Grignon DJ, Sartor O, Patel MP, Bahary JP, Zietman AL, et al. Radiation with or without antiandrogen therapy in recurrent prostate Cancer. N Engl J Med. 2017; 376(5):417-28.

16. Bales GT, Chodak GW. A controlled trial of bicalutamide versus castration in patients with advanced prostate cancer. Urology. 1996;47(1, Supplement 1):38-43.

17. Keating NL, O'Malley AJ, Smith MR. Diabetes and cardiovascular disease during androgen deprivation therapy for prostate cancer. J Clin Oncol. 2006; 24(27):4448-56.

18. Shahinian VB, Kuo Y-F, Freeman JL, Goodwin JS. Risk of fracture after androgen deprivation for prostate cancer. N Engl J Med. 2005;352(2):154-64

19. Braga-Basaria M, Dobs AS, Muller DC, Carducci MA, John M, Egan J, Basaria S. Metabolic syndrome in men with prostate cancer undergoing long-term androgen-deprivation therapy. J Clin Oncol. 2006;24(24):3979-83.

20. Gleason DF. The Veteran's administration cooperative urologic research group: histologic grading and clinical staging of prostatic carcinoma. In: Tannenbaum M, editor. Urologic pathology: The Prostate. edn. Philadelphia: Lea and Febiger; 1977. p. 171-98.

21. Epstein Jl, Allsbrook WCJ, Amin MB, Egevad LL. The ISUP grading committee: the 2005 International Society of Urological Pathology (ISUP) consensus conference on Gleason grading of prostatic carcinoma. Am J Surg Pathol. 2005;29(9):1228-42.

22. Edge SB, Byrd DR, Compton CC, Fritz AG, Greene FL, Andy Trotti I. American joint committee on Cancer: 41. Prostate. In: Edge SB, Byrd DR, Compton CC, Fritz AG, Greene FL, Andy Trotti I, American joint committee on Cancer, editors. AJCC cancer staging manual. 7th ed. New York: Springer; 2010. p. $457-68$

23. Jackson WC, Schipper MJ, Johnson SB, Foster C, Li D, Sandler HM, Palapattu GS, Hamstra DA, Feng FY. Duration of androgen deprivation therapy influences outcomes for patients receiving radiation therapy following radical prostatectomy. Eur Urol. 2016;69(1):50-7.

\section{Submit your next manuscript to BioMed Central and we will help you at every step:}

- We accept pre-submission inquiries

- Our selector tool helps you to find the most relevant journal

- We provide round the clock customer support

- Convenient online submission

- Thorough peer review

- Inclusion in PubMed and all major indexing services

- Maximum visibility for your research

Submit your manuscript at www.biomedcentral.com/submit
Biomed Central 